\title{
Autism Spectrum Disorder: the Present Perspective
}

\author{
Chaudhuri $\mathbf{S}^{1}$, Chatterjee $\mathbf{N}^{2}$ \\ ${ }^{1}$ RMO, Dr. B.C. Roy Post Graduate Institute of Pediatric Sciences, Kolkata \\ ${ }^{2}$ Professor of Pediatrics, IQ City Medical College, Durgapur, West Bengal
}

\begin{abstract}
ABSTACT
The last decade has witnessed a surge of awareness about autism among the public and professionals. Much revealing research is being done on this issue and the knowledge base has improved substantially and a set of professionals are specializing on the subject, focusing on its causative factors and management.
\end{abstract}

Autism being a disorder stemming from early childhood and the prevalence rate rising alarmingly over the years, Pediatricians are expected to play a vital role in early detection and early intervention in management of the problem. But, unfortunately, autism is not yet considered to be under the purview of pediatricians. As pediatricians, we are often perplexed when faced with such a different child in our office and either overlook the problem or hurry to hand him over to a psychiatrist, not trying to really identify and understand the problem as a medical entity ourselves. Hence better awareness among pediatricians is the need of the day.

As specialists have worked with autism over the decades, it has become clear that: autism is a disorder that involves early development, presently there is no medical answer to autism, and the only management strategy hinges largely on effective training. The earlier the training begins the better it is for the child. It is of paramount importance to start training and bring about changes by the time the child is 18 months old. This throws up interesting new challenges to the profession of pediatrics. To identify the early warning signs of autism, it is important that Pediatricians are able to recognize the signs and symptoms of autistic spectrum disorders(ASD), have a strategy for assessing them systematically, be familiar with available tools for screening as well as developmental and educational resources.

\section{INTRODUCTION}

Autism is a neuro-developmental disorder of unknown etiology, with a strong genetic basis. It is characterized by a behavioral phenotype that includes qualitative impairment in the areas of language development or communication skills, social interactions and reciprocity, imagination and play. ${ }^{1}$ To identify the early warning signs of autism, it is important that Pediatricians are able to recognize the signs and symptoms of autistic spectrum

Correspondence: Dr. Nandita Chatterjee

E-mail: chattnan@gmail.com
disorders(ASD), have a strategy for assessing them systematically, be familiar with available tools for screening as well as developmental and educational resources. $^{2}$

Different variants of the disorder have been identified which are brought under the broad umbrella of autism spectrum disorders (ASD). Autistic disorders, Aspergers disorder, childhood disintegrative disorder and Pervasive Developmental Disorder not otherwise 
specified (PDD-NOS) which were considered as different disorders previously, have all been under the purview of Autism Spectrum Disorder, as per DSM V. The 2 domains where people with ASD must show persistent deficits are a) social communication and social interaction and b) restricted and repititive patterns of behaviour (DSM V). ${ }^{3}$

\section{HISTORY}

Autism was first described by Leo Kenner, a psychiatrist at John Hopkins University, in 1943, in a group of children. In 1944, Hans Asperger, an Austrian Pediatrician described a similar condition in children, but with higher cognitive and verbal skills.

Autism first appeared as a separate entity with specific criteria in DSM-III in $1980 .^{4}$

\section{EPIDEMIOLOGY}

Current prevalence of ASD, as reported by CDC in the 2010 ADDM network report is 1in 68. It is reported to occur in all racial, ethnic and socio economic groups ${ }^{5}$. Studies in Europe, Asia and USA show a prevalence of $1 \%$ while a study from South Korea reported $2.6 \%$ prevalence. The global prevalence of autism has increased twentyfold to thirtyfold since the earliest epidemiologic studies were conducted in the late 1960s and early 1970s. This points to a steady rise in incidence to a quite alarming peak today. Although the underlying reasons for the apparent prevalence changes are difficult to study empirically, select studies suggest that much of the recent prevalence increase is likely attributable to extrinsic factors such as improved awareness and recognition and changes in diagnostic practice or service availability. ${ }^{6,7}$ It is 5 times more common in boys $(1 / 42)$ than girls $(1 / 189)^{8}$

\section{AETIOLOGY}

ASDs are a highly heritable, biologically based neurodevelopmental disorder. With an older affected sibling, the recurrence risk is reported to be $2-8 \% 0^{7,9}$ The aetiology is multi factorial, with a variety of genetic and environmental factors playing a role.

Targeted cytogenetic studies \& whole genome screens of families have been performed to identify the ASD genes, by the International Molecular Genetic Study of Autism Consortium, but interpretation of results have been challenging because of the phenotypic heterogeneity. At least 1 autism linked abnormality has been found in almost every gene, though changes noted in chromosomes $\mathrm{X}, 2,3,7,15,17 \& 22$ are most specific. ${ }^{11}$ Maternally derived $15 \mathrm{q}$ duplications are common. Male predominance also suggests an X chromosome involvement.

Autism may be idiopathic or secondary, with a co morbid syndrome or medical condition. A recent meta analysis by Chakrabarti \& Fombonne ${ }^{12}$ revealed a recognizable co-morbid condition in only $6 \%$ cases. Co-existing mental retardation was considered to be $90 \%$ before the ' 90 s, which has come down to $50 \%$ after 2000, due to increased identification of high functioning autism. ${ }^{10}$

Common diseases known to be associated with Autism are Fragile $\mathrm{X}$ syndrome( $35-50 \%$ have autistic traits), Retts syndrome (females with microcephaly, seizures $\&$ autistic traits), Tuberous sclerosis, Phenylketonuria, Fetal Alcohol Syndrome, Angelman Syndrome, Smith Lemli Opitz syndrome. 
The possibility of auto-immunologic dysfunction has not been established by any prospective studies. ${ }^{13}$

Prenatal factors like teratogens (valproic acid, thalidomide), maternal illness (rubella) are being considered as causative factors. A significant association with neonatal encephalopathy, causing six fold increase of ASD has been reported. ${ }^{17}$

Various risk factors have been mentioned, which include prematurity, low birth weight, aged parents and affected siblings, particularly twins. Identical twins have $36-95 \%$ chance of having ASD whereas the chances in non-identical twin is $0-31 \% .{ }^{16}$ Parents with a child with ASD have a $2-18 \%$ chance of having their next child affected.

\section{PATHOPHYSIOLOGY}

Presence of a definite Neuro-biologic basis of ASD is now established. The details of the alterations involved are still being investigated.

Neuro pathologic studies have revealed the following: ${ }^{1,14,15}$

- Reduced number of Purkenje cells in the cerebellum

- Abnormal maturation of the forebrain limbic system

- Frontal \& temporal lobe abnormalities

- Abnormalities in the nuclei of Diagonal band of Broca, deep cerebellar nuclei \& inferior olive

- Brainstem abnormalities \& neo cortical malformations

- Increased brain volume leading to macrocephaly (noted in 30\% cases).
- Acceleration of brain growth in the $1^{\text {st }}$ year of life, specially implicating the frontal, limbic, basal ganglia, and cerebellar regions.

- Functional MRI evidence suggests an impaired connectivity between various cortical regions.

\section{NEUROPSYCHOLOGY}

Two major categories of cognitive theories have been proposed about the links between autistic brains and behavior.

The first category focuses on deficits in social cognition. The empathizing-systemizing theory postulates that autistic individuals can systemize - that is, they can develop internal rules of operation to handle events inside the brain - but are less effective at empathizing by handling events generated by other agents. This theory is somewhat related to the earlier theory of mind approach, which hypothesizes that autistic behavior arises from an inability to ascribe mental states to oneself and others. The theory of mind hypothesis is supported by autistic children's atypical responses to the Sally-Anne test for reasoning about others' motivations. However, most studies have found no evidence of impairment in autistic individuals' ability to understand other people's basic intentions or goals; but, understanding of more complex social emotions are impairments, and, considering others' viewpoints is a difficulty.

The second category focuses on nonsocial or general processing. Executive dysfunction hypothesizes that there are deficits in working memory, planning, inhibition, and other forms of executive function. ${ }^{18}$ This theory predicts stereotyped behavior and narrow interests. 
Journal of College of Medical Sciences-Nepal, 2014, Vol-10, No-3

Weak central coherence theory hypothesizes that a limited ability to see the big picture underlies the central disturbance in autism. This theory predicts special talents and peaks in performance in autistic people

Neither category is satisfactory on its own; social cognition theories poorly address autism's rigid and repetitive behaviors, while the nonsocial theories have difficulty explaining social impairment and communication difficulties. Acombined theory based on multiple deficits may prove to be more useful. ${ }^{19}$

\section{CLINICAL PRESENTATION}

The core features of ASD include social skill defects, restricted, repetitive \& stereotyped behaviour, and language delay, but there is wide variation in presentation, with a lot of heterogeneity. Social deficits, though specific, may be subtle and go unrecognized. Parental concern is more with the speech delay. Presentations vary and some parents report that their babies were different during the first months of life, whereas delayed speech is reported during the $2^{\text {nd }}$ year of life and still others maybe normal in the early months and regress and lose skills in the $2^{\text {nd }}$ year. Some ASD children may present at school age because of poor peer interaction.

Social skill defects include:

- Being content alone, not seeking connectedness

* Poor eye contact

- Difficulty sharing the emotional state of others

- Joint attention deficit : does not enjoy sharing an object, event or emotion

- Inappropriate peer relationships
- Impaired central coherence: inability to interpret stimuli in a global way.

- Difficulty understanding the perspective of others.

- Difficulty with empathy, sharing and comforting due to severe ToM (theory of mind) deficits, referred to as 'mindblindedness'

\section{Communication Deficits:}

- Speech delay (a common presentation)

- Lack of desire to communicate

- Lack of non-verbal communication

- Speech maybe scripted and stereotyped.

- Echolalia is common

- Use of pop-up words: spontaneous, inconsistent words uttered out of context

- Use of giant words: phrases uttered as single words

- Earlier pre-speech deficits like lack of warm, joyful expression with gaze, lack of recognition of mother's voice, to $\&$ fro communication with mother, disregard for vocalization, delayed babbling etc facilitate early diagnosis.

- Regression : In 25-30\% regression of skills occur around 15-24 months, including regression of speech.

\section{Play skills}

- Lack of pretend play

- Persistence of sensory-motor and ritualistic play

- Repetitive play with lack of creativity \& imagination (egg. Spinning wheels of cars) 


\section{Behavioural Pattern:}

- Peculiar mannerisms

- Unusual attachment to objects

- Compulsive behaviour: rigidly follows certain rules like stacking, arranging in lines

- Obsessive about sameness: resistant to change

- Ritualistic behaviour: Unvarying pattern of daily activities like unchanging menu, dressing ritual etc.

- Restricted behavior is limited in focus, interest, or activity, such as preoccupation with a single television program, toy, or game

- Repetitive \& stereotyped movements like rocking, head rolling, flapping hands etc

\section{Other symptoms}

- Unusual abilities: $0.5 \%$ to $10 \%$ of individuals with ASD show unusual abilities, ranging from splinter skills such as the memorization of trivia (rote memory) to the extraordinarily rare talents of prodigious autistic savants. Many individuals with ASD show superior skills in perception and attention, relative to the general population.

- Sensory abnormalities are found in over $90 \%$ of those with autism, and are considered core features by some. ${ }^{20}$ Differences are greater for underresponsivity (for example, walking into things) than for over-responsivity (for example, distress from loud noises) or for sensation seeking (for example, rhythmic movements) ${ }^{21}$. Children with autism are less capable of simultaneously using the different senses to take in the varied information from the environment and combine them to produce a clear understanding of the world around; therefore they may have trouble responding appropriately to different stimuli.

- An estimated $60 \%-80 \%$ of autistic people have motor signs that include poor muscle tone, poor motor planning, and toe walking; deficits in motor coordination are pervasive across ASD and are greater in autism proper $^{22 .}$

- Unusual eating behavior occurs in about threequarters of children with ASD, to the extent that it was formerly a diagnostic indicator.

Common behavioural issues include Disruption/ aggression (15-64\%), Self-injurious (8-38\%), Eating disorders (25-52\%), Sleeping disorders (36\%) \& delayed Toilet training ( $40 \%$ ).

\section{DIAGNOSIS}

Diagnosis of ASD is based on specific diagnostic criteria set up by DSM V as follows:

A. Persistent deficits in social communication and social interaction across multiple contexts, as manifested by the following, currently or by history:

1. Deficits in social-emotional reciprocity, ranging, for example, from abnormal social approach and failure of normal back-andforth conversation; to reduced sharing of interests, emotions, or affect; to failure to initiate or respond to social interactions.

2. Deficits in nonverbal communicative behaviors used for social interaction, ranging, for example, from poorly integrated verbal and nonverbal communication; to 
abnormalities in eye contact and body language or deficits in understanding and use of gestures; to a total lack of facial expressions and nonverbal communication.

3. Deficits in developing, maintaining, and understanding relationships, ranging, for example, from difficulties adjusting behavior to suit various social contexts; to difficulties in sharing imaginative play or in making friends; to absence of interest in peers.

\section{Severity is based on social communication} impairments and restricted repetitive patterns of behavior (see Table 1).

B. Restricted, repetitive patterns of behavior, interests, or activities, as manifested by at least two of the following, currently or by history

1. Stereotyped or repetitive motor movements, use of objects, or speech (e.g., simple motor stereotypies, lining up toys or flipping objects, echolalia, idiosyncratic phrases).
2. Insistence on sameness, inflexible adherence to routines, or ritualized patterns or verbal nonverbal behavior (e.g., extreme distress at small changes, difficulties with transitions, rigid thinking patterns, greeting rituals, need to take same route or eat food every day).

3. Highly restricted, fixated interests that are abnormal in intensity or focus (e.g, strong attachment to or preoccupation with unusual objects, excessively circumscribed or perseverative interest).

4. Hyper- or hyporeactivity to sensory input or unusual interests in sensory aspects of the environment (e.g., apparent indifference to pain/temperature, adverse response to specific sounds or textures, excessive smelling or touching of objects, visual fascination with lights or movement).

Severity needs to be specified in each case (see Table 1).

\section{Table 1: Severity levels for autism spectrum disorder}

\begin{tabular}{|c|c|c|}
\hline Severity level & Social communication & Restricted, repetitive behaviors \\
\hline $\begin{array}{l}\text { Level 3"Requiring } \\
\text { very substantial support" }\end{array}$ & $\begin{array}{l}\text { Severe deficits in verbal and nonverbal } \\
\text { social communication skills cause } \\
\text { severe impairments in functioning, very } \\
\text { limited initiation of social interactions, and } \\
\text { minimal response to social overtures from } \\
\text { others. For example, a person with few } \\
\text { words of intelligible speech who rarely } \\
\text { initiates interaction and, when he or she } \\
\text { does, makes unusual approaches to } \\
\text { meet needs only and responds to only } \\
\text { very direct social approaches. }\end{array}$ & $\begin{array}{l}\text { Inflexibility of behavior, extreme } \\
\text { difficulty coping with change, or } \\
\text { other restricted/repetitive behaviors } \\
\text { markedly interfere with functioning } \\
\text { in all spheres. Great distress/difficulty } \\
\text { changing focus or action. }\end{array}$ \\
\hline
\end{tabular}


Journal of College of Medical Sciences-Nepal, 2014, Vol-10, No-3

\begin{tabular}{|c|c|c|}
\hline $\begin{array}{l}\text { Level 2"Requiring } \\
\text { substantial support" }\end{array}$ & $\begin{array}{l}\text { Marked deficits in verbal and } \\
\text { nonverbal social communication skills; } \\
\text { social impairments apparent even with } \\
\text { supports in place; limited initiation of } \\
\text { social interactions; and reduced or } \\
\text { abnormal responses to social overtures } \\
\text { from others. For example, a person who } \\
\text { speaks simple sentences, whose } \\
\text { interaction is limited to narrow special } \\
\text { interests, and how has markedly odd } \\
\text { nonverbal communication. }\end{array}$ & $\begin{array}{l}\text { Inflexibility of behavior, difficulty coping } \\
\text { with change, or other restricted/repetitive } \\
\text { behaviors appear frequently enough } \\
\text { to be obvious to the casual observer } \\
\text { and interfere with functioning in } \\
\text { a variety of contexts. Distress } \\
\text { and/or difficulty changing focus or action }\end{array}$ \\
\hline $\begin{array}{l}\text { Level 1"Requiring } \\
\text { support", }\end{array}$ & $\begin{array}{l}\text { Without supports in place, deficits in } \\
\text { social communication cause noticeable } \\
\text { impairments. Difficulty initiating social } \\
\text { interactions, and clear examples of } \\
\text { atypical or unsuccessful response to } \\
\text { social overtures of others. May } \\
\text { appear to have decreased interest in } \\
\text { social interactions. For example, a } \\
\text { person who is able to speak in full } \\
\text { sentences and engages in } \\
\text { communication but whose to- and-fro } \\
\text { conversation with others fails, whose } \\
\text { attempts to make friends are odd and } \\
\text { typically unsuccessful. }\end{array}$ & $\begin{array}{l}\text { Inflexibility of behavior causes } \\
\text { significant interference with } \\
\text { functioning in one or more contexts. } \\
\text { Difficulty switching between } \\
\text { activities. Problems of organization }\end{array}$ \\
\hline
\end{tabular}

C. Symptoms must be present in the early developmental period (but may not become fully manifest until social demands exceed limited capacities, or may be masked by learned strategies in later life).

D. Symptoms cause clinically significant impairment in social, occupational, or other important areas of current functioning.

E. These disturbances are not better explained by intellectual disability (intellectual developmental disorder) or global developmental delay.
Intellectual disability and autism spectrum disorder frequently co-occur; to make comorbid diagnoses of autism spectrum disorder and intellectual disability, social communication should be below that expected for general developmental level.

It needs to be specified whether the condition is accompanied by any intellectual or language impairment, any known medical or genetic condition or environmental factor or other neurodevelopmental, mental, or behavioral disorder or catatonia. 
Individuals who have marked deficits in social communication, but whose symptoms do not otherwise meet criteria for autism spectrum disorder, should be evaluated for social (pragmatic) communication disorder, the diagnostic criteria for which are:

A. Persistent difficulties in the social use of verbal and nonverbal communication as manifested by all of the following:

1. Deficits in using communication for social purposes, such as greeting and sharing information, in a manner that is appropriate for the social context.

2. Impairment of the ability to change communication to match context or the needs of the listener, such as speaking differently in a classroom than on the playground, talking differently to a child than to an adult, and avoiding use of overly formal language.

3. Difficulties following rules for conversation and storytelling, such as taking turns in conversation, rephrasing when misunderstood, and knowing how to use verbal and nonverbal signals to regulate interaction.

4. Difficulties understanding what is not explicitly stated (e.g., making inferences) and nonliteral or ambiguous meanings of language (e.g., idioms, humor, metaphors, multiple meanings that depend on the context for interpretation).

B. The deficits result in functional limitations in effective communication, social participation, social relationships, academic achievement, or occupational performance, individually or in combination.

C. The onset of the symptoms is in the early developmental period (but deficits may not become fullymanifest until social communication demands exceed limited capacities).

D. The symptoms are not attributable to another medical or neurological condition or to low abilities in the domains or word structure and grammar, and are not better explained by autism spectrum disorder, intellectual disability (intellectual developmental disorder), global developmental delay, or another mental disorder.

\section{SCREENING \& SURVEILLANCE}

With a prevalence rate of $14 / 1000$, ASD is not a rare entity and the key person who encounters this problem first is the pediatrician. As it is evident that early intervention is useful in ASD, the Pediatrician has a crucial role in identification of the cases early. For this a keen vigilance on his part is essential. Due respect should be given to the early cues picked up by parents and instead of dismissing the initial parental concern, early screening should be initiated.

A one time screening may not pick up all the cases, as features may develop at various stages of development. So a constant vigilance and regular screening is imperative on the part of the Pediatrician. Developmental surveillance should occur at every preventive visit through out childhood by attending to the parental concerns, maintaining a developmental history, making accurate observation of the child, identifying risk factors and maintaining proper documentation ${ }^{1 \cdot}$ Routine screening of all children, with 
a standardized tool like M-CHAT is recommended by AAP at 18, 24, \& 30 months of age. With an upsurge in prevalence of ASD in India, such a screening \& surveillance protocol needs to be implemented by us too. Such screening programs are inexpensive and only require an ASD awareness \& proper motivation among the pediatric fraternity. Spare 10 minutes for a child in your clinic \& you can identify the problem early and be instrumental in initiating an early intervention program in an ASD child, whereby preventing a gross lifelong disability.

\section{TREATMENT}

The main goals when treating children with autism are to lessen associated deficits and family distress, and to increase quality of life and functional independence. No single treatment is best and treatment is typically tailored to the child's needs. ${ }^{23}$ Intensive, sustained special education programs and behavior therapy early in life can help children acquire self-care, social, and job skills ${ }^{19}$ and often improve functioning and decrease symptom severity and maladaptive behaviors. ${ }^{24}$ The goal of treatment is to minimize core features, maximize functional independence, maximize quality of life \& family function.

Interventions need to be started as soon as diagnosis is suspected, not waiting for a definitive diagnosis. Regular interventions with systematically planned, developmentally appropriate educational activities is mandatory. Low student: teacher ratio and an inclusive experience with typically developing peers is essential.

Educational Interventions include methods like Applied Behavioral Analysis, Structured teaching programs like TEACCH, interventions focused on promoting Development and Relationships, Speech and Language
Therapy, including augmentative and alternative communication Social Skills Instruction, augment joint attention and OT (Sensory Integration) Therapy (evidence base not yet established)

Behavioral Treatment aims at positive behavioral support, which includes proactive arrangement of the physical environment to prevent occurrence of problem behavior, incorporation of social skill development in routine curriculum and functional behavioral analysis for individualized behavior management plans

Pharmacotherapy is not the primary treatment, but is sometimes used to ameliorate target behaviors like hyperactivity, tantrums, physical aggression, selfinjurious behavior, stereotypes, and anxiety symptoms, especially obsessive-compulsive behaviors, when they interfere with socialization, learning, health \& quality of life. Commonly used drugs include:

- Atypical neuroleptics (risperidone, olanzapine)

- Clonidine

- SSRIs (Fluoxetine)

- Alphablockers

- Methyl phenidate

- Atomoxetine

Medical management for a child with autism, as per AAP guidelines, should aim at:

- Routine immunizations as per schedule

- Treating acute illnesses

- Managing sleep dysfunction

- Treating seizures, GI disturbance, constipation etc

- Advocating normal mixed diet. Mega vitamins \& food supplements are not recommended. Dietary 
Journal of College of Medical Sciences-Nepal, 2014, Vol-10, No-3

restrictions are observed only if food allergy is proved.

It will serve to reiterate here, that there is no medication to reduce the core or biological features of autism.

\section{PROGNOSIS}

- No cure is known as yet. Some children do recover occasionally, but the actual recovery rate is not known.

- A better prognosis is associated with higher intelligence, functional speech, and less bizarre symptoms and behavior. Children acquiring language before age six and having an IQ above 50 may grow up to live self-sufficient, employed, albeit isolated, lives in the community.

- Many others remain dependent on their family for their everyday lives

- A 2004 British study of 68 adults who were diagnosed before 1980 as autistic children with IQ above 50 found that $12 \%$ achieved a high level of independence as adults, $10 \%$ had some friends and were generally in work but required some support, 19\% had some independence but were generally living at home and needed considerable support and supervision in daily living, $46 \%$ needed specialist residential provision from facilities specializing in ASD with a high level of support and very limited autonomy, and $12 \%$ needed highlevel hospital care.

- There is no increased risk of schizophrenia in adulthood

- The symptom profile for some children may change as they grow older and seizures or self-injurious behavior becomes more common.

\section{CONCLUSION}

Awareness of autism has largely increased in society over the last few years, much due to the active publicity by the media. Incidence seems to be on a constant rise. But, quite unfortunately, the pediatric fraternity in India has not yet risen to the cause. We are still not autism friendly. We often tend to dismiss the possibility by reassuring ourselves $\&$ the parents that the child will outgrow the developmental staggering pointed out by the parents. ASD is a neuro-developmental disorder with proven biological basis, and, the process begins mostly in early childhood. So who else, but the Pediatrician, should take the lead in identifying \& initiating management of these unfortunate children? Early detection and early intervention can only be possible if the Pediatrician is sensitized to the issue, as they are the first point of contact for the parents. Management may call for interventional therapy by psychologists, occupational therapists \& special educators, but a proper medical supervision of the program by a developmental pediatrician alone can convert the efforts of all the therapists into a holistic management of the child. So the time has come for us all to be a bit autism-minded, or better, development minded, and, at least some of us should opt to take up developmental pediatrics as a specialization. Much needs to be learnt $\&$ much to be done in this hitherto neglected sub-speciality.

\section{REFERENCES}

1. Shah PE, Dalton R, Boris NW. Pervasive Developmental Disorders \& Childhood Psychosis. In: Kleigman, Behrman, Jenson, Stanton eds Nelson Textbook of Pediatrics $18^{\text {th }}$ ed, Vol I; 2008:133-6.

2. Johnson CP, Myers S. Identification and Evaluation of Children with Autism Spectrum Disorders. Pediatrics. 2007; 120(5): 1183-1215 
3. American Psychiatric Association. Diagnostic and Statistical Manual of Mental Disorders, 5th Edition (DSM-III). Washington DC: American Psychiatric Association; 2013

4. American Psychiatric Association. Diagnostic and Statistical Manual of Mental Disorders, 3rd Edition (DSM-III). Washington DC: American Psychiatric Association; 1980

5. MMWR, Centres for Disease Control \& Prevention (CDC), Surveillance Summaries, March 28,2014/ 63(SS02);1-21 website: http://www.cdc.gov/mmwr/ preview $/ \mathrm{mmwrhtml} / \mathrm{ss} 6302 \mathrm{a} 1 \mathrm{htm} ? \mathrm{~s} \_\mathrm{cid}=\mathrm{ss} 6302 \mathrm{a} 1 \mathrm{~W}$

6. Blumberg SJ, Bramlett MD, Kogan MD, et al. Changes in prevalence of parent-reported autism spectrum disorder in school-aged U.S. children: 2007 to $2011-$ 2012. Natl Health Stat Rep 2013;65:1-11.

7. Schieve LA, Rice C, Devine O, et al. Have secular changes in perinatal risk factors contributed to the recent autism prevalence increase? Development and application of a mathematical assessment model. Ann Epidemiol 2011;21:930-45.

8. Asherson PJ, Curran S. Approaches to gene mapping in complex disorders and their application in child psychiatry and psychology. Br J Psychiatry. 2001;179:122-8.

9. Rutter M. Genetic influences and Autism In: Volkmar FR, Paul R, Klin A..Cohen D, eds. Handbook of autism and Pervasive Developmental Disorders. $3^{\text {rd }} \mathrm{ed}$. Vol I. Hoboken NJ: John Wiley \& Sons: 2005:425-52.

10. Levy S, Giarelli E, Lee L, et al. Autism spectrum disorders and co-occuring developmnetal, Psychiatric, and medical conditions among children in multiple populations of the United States. Journal of Developmental \& Behavioral Pediatrics 2010;31: 267-75.

11. Muhle R, Trentacoste SV, Rapin I. The Genetics of Autism. Pediatrics 2004;113(5):472-86.

12. Chakrabarti S, Fombonne E. Pervasive Developmental Disorders in Pre School Children: confirmation of high prevalence. Am J Psychiatry 2005;162: 1133-41.
13. Comi AM, Zimmerman AW, Frye VH, Law PA et al. Familial clustering of auto immune disorders and evaluation of medical risk factors in autism. $J$ Child Neurol 1999; 14: 388-94.

14. Bilder D, Pinborough-Zimmerman J, Miller J, et al. Prenatal, Perinatal and Neonatal Factors Associated with Autism Spectrum Disorders. Pediatrics 2009;123(5):1293-300.

15. Bauman ML, Kemper TL. Structural Brain Anatomy in autism: what is the evidence? In: Bauman ML, Kemper TL, eds. The Neurobiology of Autism. $2^{\text {nd }}$ ed. Baltimore, John Hopkins University Press 2005:121-35.

16. Rodier PM, Arndt TL. The Brainstem in autism. In: Bauman ML, Kemper TL, eds. The Neurobiology of Autism. $2^{\text {nd }}$ ed. Baltimore, John Hopkins University Press 2005:121-35.

17. Kolevzon A, Gross R, Reichenberg A. Prenatal and Perinatal Risk factors for autism. Arch Pediatr Adolesc Med 2007; 161:326-33.

18. Kenworthy L, Yerys BE, Anthony LG, et al. Understanding executive control in autism spectrum disorders in the lab and in the real world. Neuropsychol Rev 2008;18(4):320-38.

19. Rajendran G, Mitchell P. Cognitive theories of autism. Dev Rev 2007;27(2):224-60.

20. Geschwind DH. Advances in autism. Annu Rev Med 2009;60:367-80.

21. Ben-Sasson A, Hen L, Fluss R, et al. A meta-analysis of sensory modulation symptoms in individuals with autism spectrum disorders. J Autism Dev Disord 2009;39(1):1-11.

22. Fournier KA, Hass CJ, Naik SK, et al. Motor coordination in autism spectrum disorders: a synthesis and meta-analysis. J Autism Dev Disord 2010;40:122740.

23. Myers SM, Johnson CP. Management of children with autism spectrum disorders. Pediatrics. 2007;120(5):1162-82.

24. Rogers SJ, Vismara LA. Evidence-based comprehensive treatments for early autism. J Clin Child Adolesc Psychol 2008;37(1):8-38. 